\title{
Effect of ultrasonic treatment on formation of iron-containing intermetallic compounds in Al- Si alloys
}

\author{
Yu-bo Zhang, Svynarenko Kateryna, and *Ting-ju Li \\ Laboratory of Special Processing of Raw Materials and School of Materials Science and Engineering, Dalian University of Technology, Dalian, \\ Liaoning 116024, China
}

\begin{abstract}
Iron is generally regarded as an unavoidable impurity in Al-Si casting alloys. The acicular $\mathrm{Al}_{3} \mathrm{Fe}$ and $\beta-\mathrm{Al}_{5} \mathrm{FeSi}$ (or $\mathrm{Al}_{9} \mathrm{Si}_{2} \mathrm{Fe}_{2}$ ) are common iron-containing intermetallic compounds (IMCs) in conventional structure which have a detrimental impact on the mechanical properties. In this paper, ultrasonic field (USF) was applied to modify acicular iron phases in $\mathrm{Al}-12 \% \mathrm{Si}-2 \% \mathrm{Fe}$ and $\mathrm{Al}-2 \% \mathrm{Fe}$ alloys. The results show that the USF applied to Al-Fe alloys caused the morphological transformation of both primary and eutectic $\mathrm{Al}_{3} \mathrm{Fe}$ from acicular to blocky and granular without changes in their composition. In the case of Al-Si-Fe alloys, ultrasonic treatment led to both morphological and compositional conversion of the ternary iron IMCs. When the USF was applied, the acicular $\beta-\mathrm{Al}_{9} \mathrm{Si}_{2} \mathrm{Fe}_{2} \mathrm{was}$ substituted by star-like $\alpha-\mathrm{Al}_{12} \mathrm{Si}_{2} \mathrm{Fe}_{3}$. The modification rate of both binary and ternary iron IMCs relates to the USF treatment duration. The undercooling induced by the ultrasonic vibration contributes to the nucleation of intermetallics and can explain the transformation effect.
\end{abstract}

Key words: ultrasonic treatment; Al-Si alloy; iron-containing intermetallics; modification
CLC numbers: TG146.21
Document code: $\mathbf{A}$
Article ID: 1672-6421(2016)05-316-06

I n general, iron is regarded as an unavoidable impurity in Al-Si cast alloys which is detrimental to the mechanical properties, especially the ductility ${ }^{[1]}$. Given that the solubility of Fe in liquid Al-Si alloys is high, it is natural that iron will interfuse into the melt from steel casting tools (e.g. de-slagging ladles and stirring lances) during the casting process. The solubility of $\mathrm{Fe}$ in solid Al-Si alloys is quite low, thus, a large amount of ironcontaining intermetallic compounds (IMCs) will form in solidified structure as long as the iron content is above $0.7 \%{ }^{[2,3]}$. According to the Al-rich corner of the Al-SiFe phase diagram, iron-containing intermetallics include $\mathrm{Al}_{3} \mathrm{Fe}\left(\theta\right.$-phase), $\mathrm{Al}_{8} \mathrm{Si}_{2} \mathrm{Fe}\left(\alpha\right.$-phase) and $\mathrm{Al}_{5} \mathrm{SiFe}(\beta$-phase) ${ }^{[4,5]}$. Among those, $\mathrm{Al}_{3} \mathrm{Fe}$ and $\mathrm{Al}_{5} \mathrm{SiFe}$ phases are stable and always present in acicular shape, which has a poor bonding with the matrix, resulting in casting defects (e.g. shrinkage porosity) and a severe decrease in mechanical

\footnotetext{
* Ting-ju Li

Male, Ph.D., Professor. His research interests mainly focus on metal casting processes.

E-mail: tjuli@dlut.edu.cn
}

Received: 2015-10-02;

Accepted: 2016-01-15 properties (e.g. elongation) ${ }^{[6,7]}$. It is therefore important to eliminate the harmful effect of the acicular ironcontaining IMCs.

For the binary Al-Fe IMCs in the ternary Al-Si-Fe system, there is a simple eutectic reaction between $\alpha$-Al and $\mathrm{Al}_{3} \mathrm{Fe}$ under equilibrium conditions. It is well known that changes in cooling rate and alloy composition influence not only the size and distribution but also the type of Al-Fe IMCs ${ }^{[8-10]}$. During the non-equilibrium solidification, formation of $\mathrm{Al}+\mathrm{Al}_{3} \mathrm{Fe}$ eutectic is suppressed by metastable $\mathrm{Al}+\mathrm{Al}_{6} \mathrm{Fe}$ eutectic, with the conversion in the morphology of iron-containing constituent from acicular to granular. For this reason, rapid solidification is an optimal approach to modify the $\mathrm{Al}_{3} \mathrm{Fe}$ phase. However, the industrial application of this method is limited by the difficulties in manufacturing equipment.

The ternary iron-containing IMCs appear in a great variety of shapes, among which the two most common phases have been designated as $\alpha$-AlFeSi and $\beta$-AlFeSi. The $\alpha$ and $\beta$ phases can be distinguished by the morphology and the Fe/Si ratio ${ }^{[1-14]}$. The $\beta$-phase only exhibits a needle shape, and is always denoted as $\mathrm{Al}_{5} \mathrm{SiFe}$ or $\mathrm{Al}_{9} \mathrm{Si}_{2} \mathrm{Fe}_{2}$, with a $\mathrm{Fe} / \mathrm{Si}$ ratio of 1 . By comparison, the $\alpha$-phase appears in different 
shapes, such as Chinese script, fish bone, star or polygon. Its chemical formula is usually expressed as $\mathrm{Al}_{8} \mathrm{SiFe}_{2}, \mathrm{Al}_{12} \mathrm{Si}_{2} \mathrm{Fe}_{3}$ or $\mathrm{Al}_{20} \mathrm{Si}_{2} \mathrm{Fe}_{5}$, with a $\mathrm{Fe} / \mathrm{Si}$ ratio of more than 1.5 . In the conventional casting process, the $\alpha$-AlFeSi is metastable, and only appears at some specific composition of Al-Si-Fe alloy. For other cases, it always converts to primary $\beta$-AlFeSi by a quasi-peritectic reaction, the $\beta$-AlFeSi therefore regularly presents in castings. Manganese is a common neutralizer, which can replace iron atoms without changing the crystal structure. With the addition of $\mathrm{Mn}$, the hexagonal quaternary IMCs of compact shape are formed and the detrimental effect from acicular phase is reduced ${ }^{[15]}$. But the addition of manganese leads to an increase in the amount of IMCs, which is also harmful to Al-Si alloys' mechanical properties ${ }^{[16]}$.

Therefore, it is very important to find a method to reduce the detrimental effect of both $\mathrm{Al}_{3} \mathrm{Fe}$ and $\beta$-phase, without introducing new IMCs. Application of external fields is considered as a potential way to modify the iron-containing IMCs. It has been reported that physical fields, such as ultrasonic field (USF), and electromagnetic field, can refine the microstructure and modify secondary phases in Al-based alloys ${ }^{[17,18]}$. In the present work, the USF was applied during the solidification of Al-Fe and Al-Si-Fe alloys to study its influence on the iron-containing IMCs. By means of the microstructure evolution and changes in chemical composition, the effect of USF on the formation and conversion of iron-phases was investigated.

\section{Experimental procedure}

The alloys studied in this work, $\mathrm{Al}-2 \% \mathrm{Fe}$ and $\mathrm{Al}-12 \% \mathrm{Si}-2 \% \mathrm{Fe}$, were prepared from commercial purity $\mathrm{Al}(99.7 \%)$, pure $\mathrm{Si}$ (99.9\%), and $\mathrm{Al}-20 \% \mathrm{Fe}$ master alloy. All compositions quoted are in wt.\% unless otherwise stated. The alloys were melted in a resistance furnace at $900{ }^{\circ} \mathrm{C}$ and held for $1 \mathrm{~h}$ in order to fuse thoroughly iron-compounds in the master alloy. After holding, the melt was transferred into a preheated cylindrical graphite crucible (60 $\mathrm{mm}$ in diameter and $80 \mathrm{~mm}$ in height) and the ultrasound was applied to the melt by the preheated ultrasonic probe, the temperature of which corresponded to the temperature of the melt. The ultrasonic treatment duration was $0 \mathrm{~s}, 60 \mathrm{~s}$, $120 \mathrm{~s}$ and $300 \mathrm{~s}$ (until the melt was completely solidified). The detailed experimental parameters of USF treatment temperature are shown in Table 1. In addition, the whole process was performed in the air, but the graphite crucible was covered by asbestos felt to keep the treated Al melt in the designed temperature. After USF treatment, the melt was solidified under air cooling condition.

The ingots obtained in different experiments were $60 \mathrm{~mm}$ in diameter and $70 \mathrm{~mm}$ in height. Small samples taken from the cross-section of an ingot at $20 \mathrm{~mm}$ distance from the top were prepared for the microstructure observation by an optical microscope MEF-4A. The electron probe micro-analyzer (EPMA) was used to measure the chemical compositions of IMCs.
Table 1: Experimental parameters of USF treatment

\begin{tabular}{cccc} 
Alloy & Treatment time & $\begin{array}{c}\text { Initial } \\
\text { temperature }\end{array}$ & Final \\
Al-2Fe & $60 \mathrm{~s}$ and $120 \mathrm{~s}$ & $720^{\circ} \mathrm{C}$ & $670{ }^{\circ} \mathrm{C}$ \\
Al-2Fe & $300 \mathrm{~s}$ & $720^{\circ} \mathrm{C}$ & Solidification \\
Al-12Si-2Fe & $60 \mathrm{~s}$ and $120 \mathrm{~s}$ & $700^{\circ} \mathrm{C}$ & $650^{\circ} \mathrm{C}$ \\
$\mathrm{Al}-12 \mathrm{Si}-2 \mathrm{Fe}$ & $300 \mathrm{~s}$ & $700^{\circ} \mathrm{C}$ & Solidification \\
\hline
\end{tabular}

\section{Results}

\subsection{Effect of USF on iron phase in $\mathrm{Al}-2 \mathrm{Fe} \%$ alloy}

Figure 1 shows the influence of USF on the microstructure evolution of iron-containing IMCs in the Al-2\%Fe alloy. Without USF, the microstructure consists of coarse primary iron phase and eutectic $\mathrm{Al}+\mathrm{Al}_{3} \mathrm{Fe}$ structure (Fig. 1a). Both primary and eutectic iron phases possess acicular shape (arrow 1) with the chemical formula $\mathrm{Al}_{3} \mathrm{Fe}$ as concluded by the quantitative element analysis of EMPA (Table 2). When the USF is applied for $60 \mathrm{~s}$, the $\mathrm{Al}_{3} \mathrm{Fe}$ is refined. The morphology of primary $\mathrm{Al}_{3} \mathrm{Fe}$ converts from acicular to blocky (Fig. 1b, arrow 2), but with little change in the composition. The amount of primary $\mathrm{Al}_{3} \mathrm{Fe}$ phase, as well as the length and length-width ratio, decreases with prolonged duration of USF treatment. After treatment for $120 \mathrm{~s}$, the primary $\mathrm{Al}_{3} \mathrm{Fe}$ phase is further refined. However, the eutectic $\mathrm{Al}_{3} \mathrm{Fe}$ phase still presents an acicular shape (Fig. 1c, arrows 3 and 4). It is a little difficult to distinguish primary and eutectic $\mathrm{Al}_{3} \mathrm{Fe}$ phase due to their similar size. When the USF is applied to solidification (about $300 \mathrm{~s}$ ), it is clearly observed in Fig. 1d that, the eutectic $\mathrm{Al}_{3} \mathrm{Fe}$ is evenly distributed in the grain boundary of $\alpha-\mathrm{Al}$ and completely refined to granular or short rod-like shape (arrows 5 and 6). The change of composition from $\mathrm{Al}_{3} \mathrm{Fe}$ to $\mathrm{Al}_{3.5} \mathrm{Fe}$ (as listed in Table 2) is considered to result from the measured error, due to the similar size between the eutectic $\mathrm{Al}_{3} \mathrm{Fe}$ phase and point analysis of EMPA ( $1 \mu \mathrm{m}$ in dia.). The results of morphological analysis of iron-containing phases are presented in Fig. 2. It is clear that the size of primary $\mathrm{Al}_{3} \mathrm{Fe}$ is obviously reduced with the USF treatment of any duration. On the contrary, the appearance of eutectic $\mathrm{Al}_{3} \mathrm{Fe}$ changes greatly only in the case when the USF is applied for $300 \mathrm{~s}$.

According to the aforementioned results and analysis, it can be concluded that the USF leads to morphological modification of the binary $\mathrm{Al}_{3} \mathrm{Fe}$ phase without changing its composition.

\subsection{Effect of USF on iron-containing phases in $\mathrm{Al}-12 \% \mathrm{Si}-2 \mathrm{Fe} \%$ alloy}

The microstructure of the $\mathrm{Al}-12 \% \mathrm{Si}-2 \% \mathrm{Fe}$ alloy treated by the USF is shown in Fig. 3. The typical as-cast microstructure of the Al-12\% Si-2\%Fe alloy (Fig. 3a) consists of coarse acicular iron phases and $\mathrm{Al}+\mathrm{Si}$ eutectic. When the USF is applied for $60 \mathrm{~s}$, a number of star-like iron-containing IMCs appear in the microstructure (Fig. 3b). However, the acicular intermetallics are still present in the matrix, although their amount decreases with prolonged treatment duration, as shown in Fig. 3c. With the USF applied for $300 \mathrm{~s}$, there is no acicular phase in the 

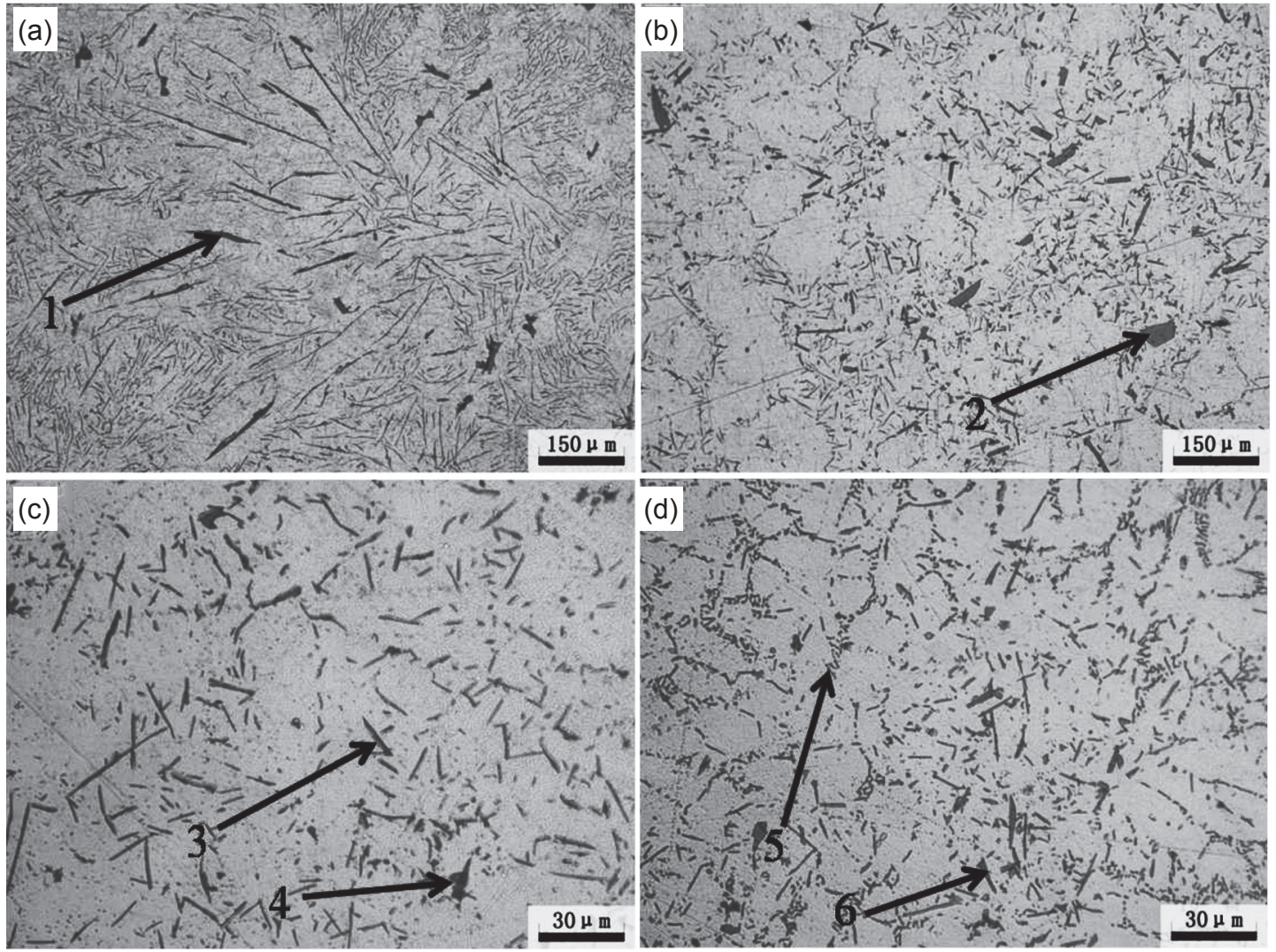

Fig. 1: Microstructures of Al-2\%Fe alloy under USF with applied time of (a) $0 \mathrm{~s}$, (b) $60 \mathrm{~s}$, (c) $120 \mathrm{~s}$ (d) $300 \mathrm{~s}$

Table 2: Composition analysis of iron phases by EPMA (at.\%)

\begin{tabular}{|c|c|c|c|}
\hline \multirow{2}{*}{ Point } & \multicolumn{2}{|c|}{ Chemical composition } & \multirow{2}{*}{$\begin{array}{c}\text { Chemical } \\
\text { formula }\end{array}$} \\
\hline & $\mathrm{Fe}$ & $\mathbf{A l}$ & \\
\hline 1 & 24.625 & 75.375 & $\mathrm{Al}_{3} \mathrm{Fe}$ \\
\hline 2 & 24.149 & 75.851 & $\mathrm{Al}_{3} \mathrm{Fe}$ \\
\hline 3 & 24.804 & 75.186 & $\mathrm{Al}_{3} \mathrm{Fe}$ \\
\hline 4 & 25.173 & 74.867 & $\mathrm{Al}_{3} \mathrm{Fe}$ \\
\hline 5 & 21.816 & 78.184 & $\mathrm{Al}_{3.5} \mathrm{Fe}$ \\
\hline 6 & 24.525 & 75.475 & $\mathrm{Al}_{3} \mathrm{Fe}$ \\
\hline
\end{tabular}

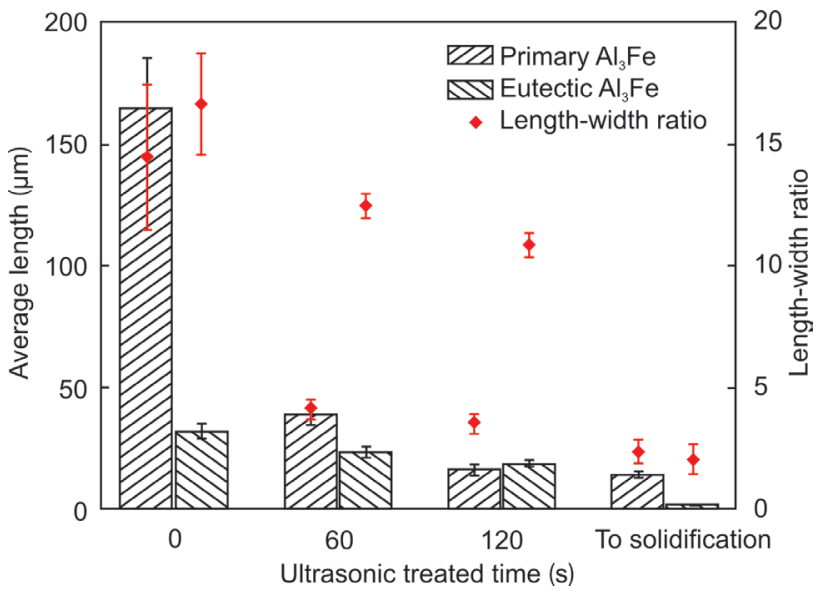

Fig. 2: Morphological analysis of iron-containing phases in $\mathrm{Al}-2 \% \mathrm{Fe}$ alloy under USF microstructure (Fig. 3d), only star-like iron-containing IMCs can be observed.

Figure 4 shows the morphological analysis of the ironcontaining phases. It can be seen that the average length and length-width ratio of the iron-containing inclusions obviously decrease with the application of USF. Moreover, USF can change not only the morphology of iron phases, but also their composition. The average composition of iron phases measured by EPMA is listed in Table 3. The results indicate that the as-cast acicular iron phase is $\mathrm{Al}_{9} \mathrm{Si}_{2} \mathrm{Fe}_{2}$, with no changes in the composition regardless of the USF treatment (as highlighted by the arrows 1, 2 in Fig. 3). In comparison, the star-like phase (as highlighted by the arrows 3-6 in Fig. 3) has a different composition and its chemical formula is $\mathrm{Al}_{2} \mathrm{Si}_{2} \mathrm{Fe}_{3}$, corresponding to the $\alpha$-AlSiFe as reported in the literature [12-14].

\section{Discussion}

As shown in Figs. 1 and 3, after the application of USF, both the primary and eutectic $\mathrm{Al}_{3} \mathrm{Fe}$ are modified in Al-Fe alloy, and the metastable $\alpha-\mathrm{Al}_{12} \mathrm{Si}_{2} \mathrm{Fe}_{3}$ substitutes the stable $\beta-\mathrm{Al}_{9} \mathrm{Si}_{2} \mathrm{Fe}_{2}$ in the $\mathrm{Al}-\mathrm{Si}-\mathrm{Fe}$ alloy. Furthermore, the modification rate increases with an increase in the USF applied duration.

The influence of USF on materials processing has been studied for several decades, and the cavitation is considered to be the most influential phenomenon of USF ${ }^{[19]}$. The cavitation is the formation, growth and immediate implosion of the cavitation bubbles in liquid, accompanied by a sharp increase in localized pressure to a peak value of $400 \mathrm{MPa}^{[20]}$. According to the 

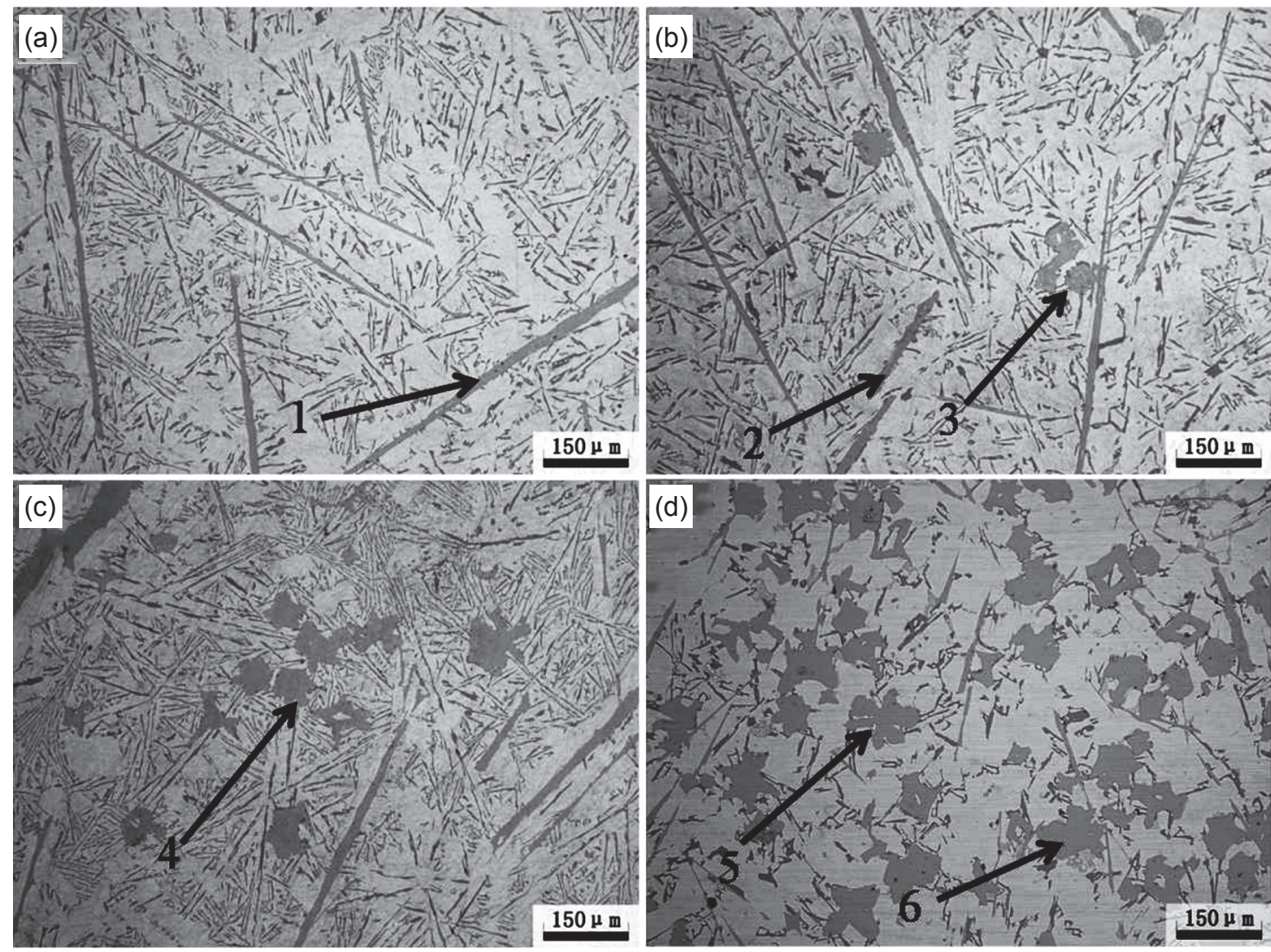

Fig. 3: Microstructures of Al-12\%Si-2\%Fe alloy under USF applied for (a) $0 \mathrm{~s}$, (b) $60 \mathrm{~s}$, (c) $120 \mathrm{~s}$ and (d) $300 \mathrm{~s}$

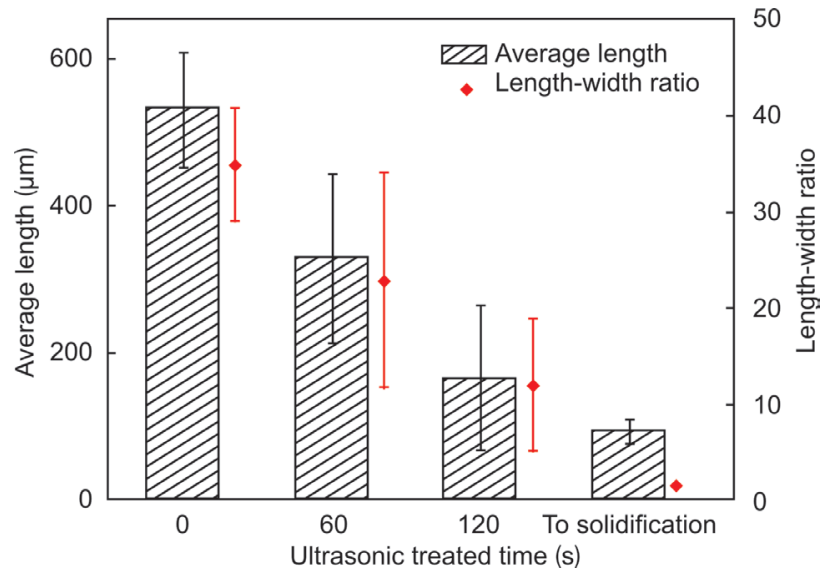

Fig. 4: Morphological analysis of iron-containing phases in $\mathrm{Al}-12 \% \mathrm{Si}-2 \% \mathrm{Fe}$ alloy under USF

Table 3: Composition analysis of iron phases by EPMA (at.\%)

\begin{tabular}{|c|c|c|c|c|c|}
\hline \multirow{2}{*}{ Point } & \multicolumn{3}{|c|}{ Chemical composition } & \multirow[b]{2}{*}{$\mathrm{Fe} / \mathrm{Si}$} & \multirow{2}{*}{ Chemical formula } \\
\hline & $\overline{\mathrm{Al}}$ & $\mathrm{Fe}$ & $\overline{\mathrm{Si}}$ & & \\
\hline 1 & 69.125 & 15.760 & 15.115 & 1.04 & $\beta-\mathrm{Al}_{9} \mathrm{Si}_{2} \mathrm{Fe}_{2}$ \\
\hline 2 & 64.341 & 16.718 & 17.941 & 0.93 & $\beta-\mathrm{Al}_{9} \mathrm{Si}_{2} \mathrm{Fe}_{2}$ \\
\hline 3 & 71.018 & 17.435 & 11.547 & 1.51 & $\alpha-\mathrm{Al}_{12} \mathrm{Si}_{2} \mathrm{Fe}_{3}$ \\
\hline 4 & 73.601 & 16.127 & 10.272 & 1.57 & $\alpha-\mathrm{Al}_{12} \mathrm{Si}_{2} \mathrm{Fe}_{3}$ \\
\hline 5 & 72.365 & 16.204 & 11.431 & 1.42 & $\alpha-\mathrm{Al}_{12} \mathrm{Si}_{2} \mathrm{Fe}_{3}$ \\
\hline 6 & 73.182 & 16.641 & 10.177 & 1.64 & $\alpha-\mathrm{Al}_{12} \mathrm{Si}_{2} \mathrm{Fe}_{3}$ \\
\hline
\end{tabular}

Clausius-Clapeyron equation, the increased local pressure will increase the local equilibrium melting point, suggesting that USF can bring about undercooling to the treated melts. In addition, the cavitation can clean the surface of insoluble inclusions and improve their wettability. The forced wetting of inclusions will increase the possibility of nucleation cores ${ }^{[21]}$. Thus, the application of USF can enhance not only the undercooling nucleation but also the heterogeneous nucleation.

In the case of the $\mathrm{Al}-2 \% \mathrm{Fe}$ alloy, which is a typical binary eutectic system, occurrence of cavitation can lead to the formation of a large amount of nucleation sites in the melt for both, primary and eutectic $\mathrm{Al}_{3} \mathrm{Fe}$ phases. When USF is applied for $60 \mathrm{~s}$ and $120 \mathrm{~s}$, the corresponding temperature of the melt is about $670{ }^{\circ} \mathrm{C}$, which is lower than the liquidus temperature $\left(685^{\circ} \mathrm{C}\right)$, but higher than the eutectic temperature $\left(655^{\circ} \mathrm{C}\right)$, as shown in Fig. 5(a) of the Al-Fe binary phase diagram. The USF works in the liquid and the solid-liquid zone, during this duration only the nucleation of primary $\mathrm{Al}_{3} \mathrm{Fe}$ happens, therefore, obvious modification of primary $\mathrm{Al}_{3} \mathrm{Fe}$ can be observed in the corresponding microstructure. For the case of $300 \mathrm{~s}$ treatment, the temperature of USF termination was lower than the eutectic temperature, i.e., the application of USF lasts to the occurrence of the eutectic reaction. The eutectic structure is influenced by the ultrasonic cavitation induced nucleation. Thus, both primary and eutectic $\mathrm{Al}_{3} \mathrm{Fe}$ are modified when USF is applied to solidification.

As for the ternary Al-Si-Fe system, the $\alpha$-AlFeSi phase is metastable in the conventional casting process. It has been reported that the $\alpha$-phase begins to crystallize at $751{ }^{\circ} \mathrm{C}$ and 

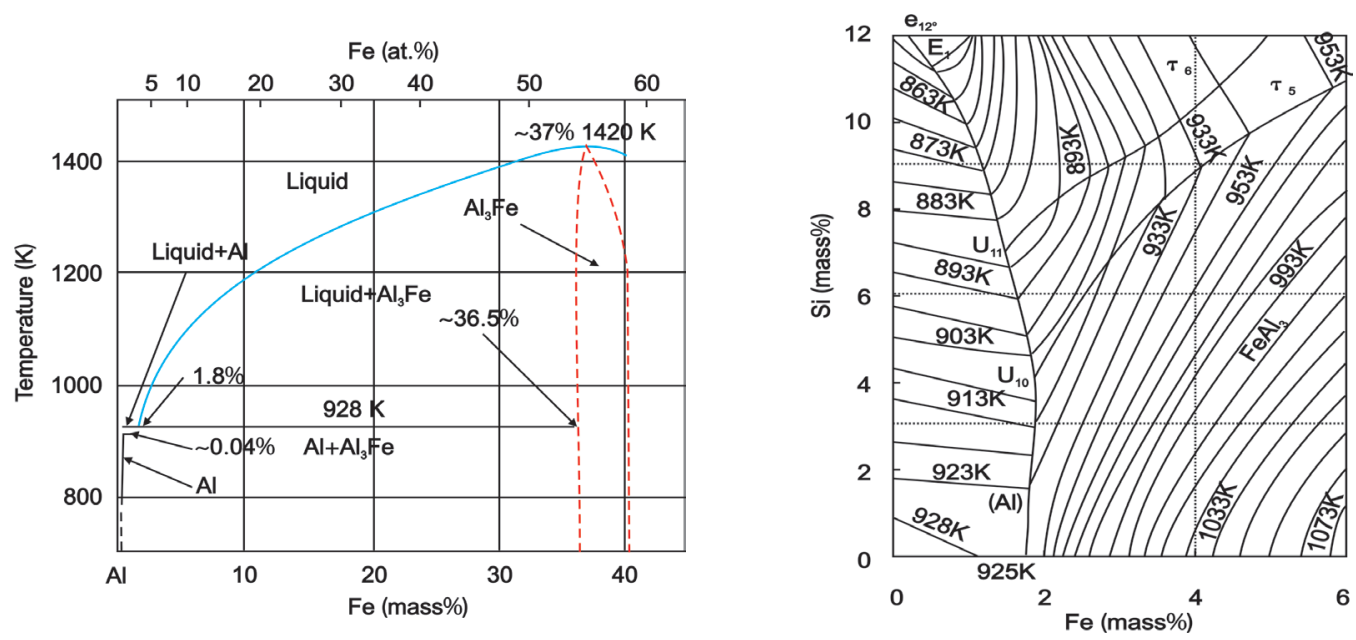

Fig. 5: In Al-rich region (a) Al-Fe phase diagram ${ }^{[22]}$ and (b) liquidus surface of $\mathrm{Al}-\mathrm{Fe}-\mathrm{Si}{ }^{[23]}$

continues to precipitate until the temperature drops to $628^{\circ} \mathrm{C}$. But it will convert to the primary $\beta$-AlFeSi phase by the quasiperitectic reaction at $612{ }^{\circ} \mathrm{C}^{[4,12]}$ :

$$
\text { Liq. }+\alpha \rightarrow \mathrm{Al}+\beta
$$

The formation of $\beta$-phase lasts till the Al-Si binary eutectic temperature of $577^{\circ} \mathrm{C}$. Hence, only acicular $\beta$-AlFeSi is presented in the solidification structure.

When USF is applied to the melt at $700{ }^{\circ} \mathrm{C}$, the nucleation process of $\alpha$-phase is promoted due to the cavitation-induced undercooling, and these nuclei then grow up. When the $\alpha$-phase has grown to a certain size, its transformation to the $\beta$-phase is impeded due to lack of solute atoms in the surrounding melt. When the USF is applied for $60 \mathrm{~s}$ and $120 \mathrm{~s}$, the treatment terminates at about $650{ }^{\circ} \mathrm{C}$ (which is higher than the liquidus of the Al-12Si-2Fe alloy as shown in Fig. 5b), and the size of the precipitated $\alpha$-phase reached a critical value. These particles will therefore continue to grow to a star-like or blocky shape instead of the transformation into the acicular $\beta$-phase even without USF. At the same time, some of $\alpha$-phase nucleated at the temperature range from $650{ }^{\circ} \mathrm{C}$ to $628{ }^{\circ} \mathrm{C}$, grows without USF treatment and then participates in the quasi-peritectic reaction at $612{ }^{\circ} \mathrm{C}$, resulting in the formation of acicular $\beta$-phase. Thus, both $\alpha$-phase and $\beta$-phase can be observed in Figs. 3b and 3c. When the USF is applied for 300 s, i.e. till the melt solidifies, the improved effect of USF on the nucleation and growth of $\alpha$-phase is persistent. In this case, most of iron atoms present in the melt are consumed and the growth of $\alpha$-phase nuclei is facilitated while the transformation to $\beta$-phase is suppressed completely. For this reason, only star-like $\alpha$-phase can be observed in the microstructure.

\section{Conclusions}

The influences of USF on the morphology and composition of binary and ternary iron-containing IMCs in Al- $2 \% \mathrm{Fe}$ and Al$12 \% \mathrm{Si}-2 \% \mathrm{Fe}$ alloys were studied, and the main findings can be concluded as follows:

(1) The application of USF leads to the morphological modification of both primary and eutectic $\mathrm{Al}_{3} \mathrm{Fe}$ phases in $\mathrm{Al}-$
$2 \% \mathrm{Fe}$, with the relation of transition rate to the USF applied duration.

(2) The application of USF facilitates the formation of starlike $\alpha-\mathrm{Al}_{12} \mathrm{Si}_{2} \mathrm{Fe}_{3}$ phase and suppresses its conversion into the acicular $\beta-\mathrm{Al}_{9} \mathrm{Si}_{2} \mathrm{Fe}_{2}$ phase in $\mathrm{Al}-12 \% \mathrm{Si}-2 \% \mathrm{Fe}$ alloy.

(3) The ultrasonic cavitation-induced undercooling facilitates the nucleation of iron phase, and is responsible for the morphological modification and phase transformation of ironcontaining IMCs.

\section{References}

[1] Seifeddine S, Johanson S, and Svensson I L. The Influence of Cooling Rate and Manganese Content on the $\mathrm{B}-\mathrm{Al}_{5} \mathrm{FeSi}$ Phase Formation and Mechanical Properties of Al-Si-Based Alloys. Materials Science and Engineering: A, 2008, 490(1): 385-390.

[2] Narayanan L A, Samuel F, and Gruzleski J. Crystallization Behavior of Iron-Containing Intermetallic Compounds in 319 Aluminum Alloy. Metallurgical and Materials Transactions A, 1994, 25(8): 1761-1773.

[3] Eidhed W, Tezuka H, and Sato T. Effects of $\mathrm{Cr}$ and $\mathrm{Cr} / \mathrm{Mn}$ Combined Additions on Semi-Solid Microstructures of Al-MgSi Alloys Produced by D-Ssf Process. Journal of Materials Science \& Technology, 2008, 24(1): 21-24.

[4] Lee S, Kim B, and Lee S. Prediction of Solidification Paths in Al-Si-Fe Ternary System and Experimental Verification: Part I. Fe-Containing Hypoeutectic Al-Si Alloys. Materials Transactions, 2011, 52(5): 1053-1062.

[5] Du Y, Schuster J C, Liu Z K, et al. A Thermodynamic Description of the Al-Fe-Si System over the Whole Composition and Temperature Ranges A Hybrid Approach of Calphad and Key Experiments. Intermetallic, 2008, 16(4): 554-570.

[6] Mondolfo L F. Aluminum Alloys: Structure and Properties. Butterworths, London, 1976.

[7] Couture A. Iron in Aluminum Casting Alloys - a Literature Survey. AFS International Cast Metal Journal, 1981, 6(4): 9-17.

[8] Adam C M, Hogan L M. Crystallography of the $\mathrm{Al}^{-} \mathrm{Al}_{3} \mathrm{Fe}$ Eutectic. Acta Metallurgical Materials, 1975, 123(3): 345-354.

[9] Hughes I and Jones H. Coupled Eutectic Growth in Al-Fe Alloys. Journal of Materials Science, 1976, 11(10): 1781-1793.

[10] Hollingsworth E H and Willet R E. Identification of a new Al-Fe constituent, FeAl6. Trans. Met. Soc. AIME., 1962, 224: 2. 
[11] Asensio-Lozano $\mathrm{J}$ and Suárez-Peňa $\mathrm{B}$. Influence of $\mathrm{Sr}$ Modification and Ti Grain Refinement on the Morphology of Re-Rich Precipitates in Eutectic Al-Si Die Cast Alloys. Scripta Materialia, 2006, 54(9): 1543-1548.

[12] Gupta S P. Intermetallic Compound Formation in Fe-AI-S Ternary System: Part I. Materials Characterization, 2002, 49(4): 269-291.

[13] Kral M, Mclntyre H, and Smillie M. Identification of Lntermetallic Phases in a Eutectic Al-Si Casting Alloy Using Electron Backscatter Diffraction Pattern Analysis. Scripta Materialia, 2004, 51(3): 215-219.

[14] Kral M. A Crystallographic Identification of Intermetallic Phases in Al-Si Alloys. Materials Letters, 2005, 59(18): 2271-2276.

[15] Shabestari S, Mahmudi T, Emamy M, et al. Effect of $\mathrm{Mn}$ and $\mathrm{Sr}$ on Intermetallics in Fe-Rich Eutectic Al-Si Alloy. International Journal of Cast Metals Research, 2002, 15(1):17-24.

[16] Zang Y, Jie J, Gao Y, et al. Effects of Ultrasonic Treatment on the Formation of Iron-Containing Intermetallic Compounds in Al-12\%Si-2\%Fe Alloys. Intermetallics, 2013, 42(9): 120-125.

[17] Jie J C, Zou Q C, Sun J L, et al. Separation Mechanism of the Primary Si Phase from the Hypereutectic Al-Si Alloy Using a Rotating Magnetic Field during Solidification. Acta Materialia, 2014, 72(7): 57-66.
[18] Zhang Y, Jie J, Wu L, et al. Microstructure and Mechanical Properties of Al-8PctSi Alloy Prepared by Direct Chill Casting under Electromagnetic and Ultrasonic Fields. Metallurgical \& Materials Transactions Part A, 2014, 45(4): 2014-2022.

[19] Eskin G. Principles of Ultrasonic Treatment: Application for Light Alloys Melts. Advanced Performance Materials, 1997, 4(2): 223-232.

[20] Shu D, Sun B, Mi J, et al. A High-speed Imaging and Modeling Study of Dendrite Fragmentation Caused by UItrasonic Cavitation. Metallurgical and Materials Transactions A, 2012, 43(10): 3755-3766.

[21] Atamanenko T, Eskin D, Zhang L, et al. Criteria of Grain Refinement Induced by Ultrasonic Melt Treatment of Aluminum Alloys Containing $\mathrm{Zr}$ and $\mathrm{Ti}$. Metallurgical and Materials Transactions A, 2010, 41(8): 2056-2066.

[22] Zhou Z. Research on Melt Treatment and Solidification Characteristics of Al-Fe Alloy. Ph. D. dissertation, Shenyang University of Technology, 2008. (In Chinese)

[23] Osawa Y, Takamori S, Kimura T, et al. Morphology of Intermetallic Compounds in Al-Si-Fe Alloy and Its Control by Ultrasonic Vibration. Materials Transactions, 2007, 48(9): 2467-2475. 